\title{
A importância da alimentação na hipertrofia
}

\author{
The importance of nutrition in hypertrophy \\ La importancia de la nutrición en la hipertrofia
}

Recebido: 1910/2021 | Revisado: 28/10/2021 | Aceito: 05/11/2021 | Publicado: 08/11/2021

Vitória Gomes Abreu

ORCID: https://orcid.org/0000-0003-3971-3828 Faculdade Integrada Carajás, Brasil E-mail: gomesabreuvitoria@gmail.com Rhaylla Sabina da Silva Lopes ORCID: https://orcid.org/0000-0002-7178-5584 Faculdade Integrada Carajás, Brasil

E-mail: rhayllasabinalopes@gmail.com

Eduarda Moreira Lima

ORCID: https://orcid.org/0000-0002-5933-8888 Faculdade Integrada Carajás, Brasil E-mail: eduardamoreira0911@gmail.com

Jânio Sousa Santos

ORCID: https://orcid.org/0000-0003-2180-1109 Faculdade Integrada Carajás, Brasil E-mail: santosjs.food@gmail.com

\begin{abstract}
Resumo
Alimentação adequada é um dos fatores determinantes para uma boa nutrição, qualidade de vida e melhora do desempenho físico. A busca por alimentação saudável e adequada está entre as prioridades de quem busca a hipertrofia muscular. Nesse sentido, o presente estudo tem o objetivo de verificar a importância da alimentação na hipertrofia, esclarecendo como obter melhora na musculatura e no ganho de massa corporal por meio da prática de exercícios físicos associadas a uma boa alimentação. O trabalho consiste em uma pesquisa bibliográfica, que trouxe dados da importância da alimentação e sua correlação com os treinos de hipertrofia. Como resultados, apresentou algumas dietas usuais; suplementos alimentares, como Whey protein, creatina e glutamina, utilizados para potencializar o desempenho em treinos e a alimentação adequada para a hipertrofia. Em destaque, ressalta-se carboidratos e proteínas como principais componentes alimentares, bem como a hidratação considerada um fator importante no processo. Mostrou ainda, que a quantidade de energia fornecida pelos alimentos, dependem da intensidade, duração e cronicidade do treino, não havendo um padrão que pode ser adotado por todos. Portanto, é necessário acompanhamento profissional de forma a prever a necessidade nutricional de cada pessoa, com base em seus objetivos desejados, promovendo assim, não somente a hipertrofia, mas manutenção e prevenção da saúde.
\end{abstract}

Palavras-chave: Alimentação saudável; Hipertrofia; Qualidade de vida.

\begin{abstract}
Adequate nutrition is one of the determining factors for good nutrition, quality of life and improved physical performance. The search for healthy and adequate food is among the priorities of those seeking muscle hypertrophy. In this sense, the present study aims to verify the importance of nutrition in hypertrophy, clarifying how to obtain an improvement in musculature and in body mass gain through the practice of physical exercises associated with good nutrition. The work consists of a bibliographical research, which brought data on the importance of nutrition and its correlation with hypertrophy training. As a result, he presented some usual diets; food supplements such as Whey protein, creatine and glutamine, used to enhance performance in training and adequate nutrition for hypertrophy. As a highlight, carbohydrates and proteins are highlighted as the main food components, as well as hydration is considered an important factor in the process. It also showed that the amount of energy provided by food depends on the intensity, duration and chronicity of the training, with no standard that can be adopted by everyone. Therefore, professional monitoring is necessary in order to predict the nutritional needs of each person, based on their desired goals, thus promoting not only hypertrophy, but also maintenance and prevention of health.
\end{abstract}

Keywords: Healthy eating; Hypertrophy; Quality of life.

\section{Resumen}

Una nutrición adecuada es uno de los factores determinantes para una buena nutrición, calidad de vida y mejora del rendimiento físico. La búsqueda de una alimentación sana y adecuada es una de las prioridades de quienes buscan la hipertrofia muscular. En este sentido, el presente estudio tiene como objetivo verificar la importancia de la nutrición en la hipertrofia, aclarando cómo obtener una mejora en la musculatura y en la ganancia de masa corporal a través de 
la práctica de ejercicios físicos asociados a una buena nutrición. El trabajo consiste en una investigación bibliográfica, que aportó datos sobre la importancia de la nutrición y su correlación con el entrenamiento en hipertrofia. Como resultado, presentó algunas dietas habituales; Complementos alimenticios como la proteína de suero, la creatina y la glutamina, utilizados para mejorar el rendimiento en el entrenamiento y una nutrición adecuada para la hipertrofia. Como destaque, los carbohidratos y las proteínas se destacan como los principales componentes alimentarios, así como la hidratación se considera un factor importante en el proceso. También mostró que la cantidad de energía que aporta la comida depende de la intensidad, duración y cronicidad del entrenamiento, sin un estándar que pueda ser adoptado por todos. Por tanto, el seguimiento profesional es necesario para predecir las necesidades nutricionales de cada persona, en función de sus objetivos deseados, promoviendo así no solo la hipertrofia, sino también el mantenimiento y prevención de la salud.

Palabras clave: Alimentación saludable; Hipertrofia; Calidad de vida.

\section{Introdução}

Nos dias atuais a importância da alimentação vem se destacando por proporcionar uma boa nutrição, qualidade de vida e melhora no desempenho físico das pessoas.

Vale ressaltar que para alcançar todos os parâmetros estéticos atuais, voltados para a hipertrofia, é necessário além de uma boa alimentação, a prática de treinamento físico, o uso de suplementações, se necessário, e um bom acompanhamento profissional (Gonçalves \& Rocha, 2019).

Frente ao cenário da crescente busca por um estilo de vida mais saudável, observa-se a busca por suplementos alimentares, que entra nesse contexto com o objetivo de adicionar substância específica à dieta do indivíduo, de forma a suprir as necessidades do organismo. Contudo, é importante ressaltar que apesar de suas positividades, o mesmo deve ser indicado sob orientação profissional, e não substitui uma alimentação saudável e balanceada, tendo em vista que a alimentação é fundamental para o alcance de uma melhor performance no desempenho físico, além de atender as necessidades do corpo no pré e pós treino.

A pesquisa se justifica, em vista à crescente preocupação dos praticantes de atividade física com a alimentação e o baixo nível de conhecimento por parte dos esportistas acerca do assunto.

Diante disso o objetivo deste estudo é analisar a importância da alimentação na hipertrofia, esclarecendo como obter melhora na musculatura e no ganho de massa corporal por meio da prática de exercícios físicos associadas a uma boa alimentação, na qual mantém o organismo em estado de saúde, ou seja, com osso e dentes fortes, peso e estatura de acordo com o biótipo do indivíduo, boa disposição, resistência às enfermidades, vontade de trabalhar e se divertir. E, para que isso ocorra é necessária uma dieta balanceada que contenha variados nutrientes com múltiplas funções (Monteiro \& Costa, 2004).

Amaral (2008) afirma que a formação de hábitos alimentares saudáveis é um processo que se inicia desde o nascimento, com as práticas alimentares introduzidas nos primeiros anos de vida pelos pais, primeiros responsáveis pela formação do indivíduo.

Segundo a Dartora, Valduga e Venquiaruto (2006) a alimentação é algo essencial na manutenção da saúde. É importante ter refeições balanceadas, constituindo um dos recursos utilizados pela medicina preventiva, para determinar uma vida saudável e duradoura.

E, para que haja uma compreensão maior sobre o tema, faz-se necessário a conscientização acerca da alimentação como fator de grande contribuição para melhor qualidade de vida, permitindo o incentivo à promoção da saúde por meio da educação nutricional, tornando essa, portanto, uma necessidade atual.

\section{Metodologia}

Para atingir o objetivo proposto, foi realizado um estudo qualitativo de revisão bibliográfica, tendo como meios de fundamentação documentos cientificos disponíveis online. Assim fazemos um levantamento bibliográfico, com intuito de 
confirmar os objetivos da pesquisa por meio da investigação de estudos sobre a alimentação saudável na hipertrofia.

As buscas dos dados científicos foram realizadas em bases de dados como, Scielo, Pub Med, e Medlline, que permitiram uma melhor análise e apontamento para as abordagens sobre a alimentação na hipertrofia. Para a elaboração do trabalho, foi seguida a metodologia proposta por Pereira et al., (2018), que afirmam que o método científico é um trabalho sistemático, na busca de respostas às questões estudadas, sendo este, o caminho que se deve seguir para levar à formulação de uma teoria científica.

\section{Resultados e Discussão}

\section{Low Carb}

A sociedade atual consome alimentos de alto teor calórico e gasta pouca energia, ocasionando um grande aumento de obesidade, o excesso de peso vem se tornando um dos maiores risco a saúde, responsável pelo aumento de doenças não transmissíveis (DCNT) como obesidade, hipertensão, diabetes, câncer e consequentemente induzindo o número de morbidade e mortalidade, então é necessário usar estratégias para seu controle, a alimentação tem um papel extremamente importante no tratamento (Cordeiro, Salles \& Azevedo, 2017).

O primeiro processo é a perca de peso, ela é dividida em duas partes, a diminuição de estoque de água intracelular reduzindo índices glicêmicos e hormonais, diminuição de concentração de glicogênio diminuindo a gordura corporal e na segunda fase o peso passa um período sem fluir, pode durar meses e até mesmo anos (Thomas et al., 2014).

A dieta low carb é de baixa ingestão de carboidratos focando na produção de energia por meio de proteínas e gorduras, são definidas com a ingestão inferior de $200 \mathrm{~g}$ e carboidratos por dia usando de 50 a $150 \mathrm{~g}$ por dia de energia vindo de carboidratos (Cordeiro, Salles \& Azevedo, 2017).

Após a redução de carboidratos da dieta o metabolismo sofre alteração e os ácidos graxos passam e ser novas fonte de energia, potencializando a oxidação da gordura e aumentando o gasto energético assim maximizando a perca de gordura. Eficaz na perda de peso e diminuição da massa gorda, estímulo da libido, aumento do HDL, diminuição de triglicerídeos, controle glicêmico e redução de doenças cardiovasculares, melhor controle da glicemia, diabete mellito tipo 2, redução e perca de peso em indivíduos com obesidade (Cordeiro, Salles \& Azevedo, 2017).

Devido à baixa ingestão de carboidrato pode prejudicar o rendimento da atividade física, aumentando a fadiga durante o exercício. Aumento de peso da gordura corporal após adaptação metabólica, aumento de peso subsequente. Resultados insatisfatórios sobre disposição físico, ganho de peso posteriormente, baixa adesão com restrição de carboidrato (Cordeiro, Salles \& Azevedo, 2017).

\section{Jejum intermitente}

O jejum intermitente é uma prática realizada desde a antiguidade, quando os mulçumanos faziam abstinência das refeições ao amanhecer do dia até o pôr do sol, alimentando em janela de curto período, no período de jejum pode consumir somente líquidos, água, café e chás sem adição de açúcares. Durante a prática do jejum é indicado consumir alimentos saudáveis carboidratos complexos, proteínas e fibras, o primeiro tipo de jejum é o de $12 \mathrm{~h}$ consecutivas e nas $12 \mathrm{~h}$ seguidas se alimenta normalmente, o segundo é o $1618 \mathrm{~h}$ sendo $16 \mathrm{~h}$ em jejum e $8 \mathrm{~h}$ comendo normalmente, o jejum é indicado para pessoas saudáveis e sem nenhuma patologia (Bicalho, De Almeida \& Gomes, 2020).

O jejum intermitente atua na citrulína que promove ações genômicas importantes para a saúde como resistência ao estres, autofagia, controle da glicose do metabolismo lipídico, biogênese mitocondrial e sobrevivência da célula. Todas essas ações metabólicas promovem benefício a saúde que vão além da perca de peso, um dos benéficos do jejum é a promoção de energia através da gordura (Moraes, 2016). 


\section{Obesidade infantil uma consequência das escolhas alimentares}

Penha et al. (2018) cita que por muitos anos era entendido que as complicações vindas da obesidade ocorriam exclusivamente no público adulto, mesmo compreendendo seu efeito no público infantil. Existem estudos que comprovam as consequências negativas do ganho de peso no público infantil e seu consequente prejuízo na saúde, e a responsabilidade por isso é uma alimentação inadequada, principalmente ligada à falta de atividade física, e a um número crescente de doenças crônicas, além da exclusão que essas crianças sofrem em consequência do bullying. "Em 2016, estima-se que 42 milhões de crianças menores de 5 anos estavam acima do peso ou obesas; quase três quartos deles vivem na Ásia e África" (OMS, 2018).

Para Machado, Ferreira e Rangel (2019), a criança é o reflexo dos pais, portanto, se eles não dispuserem de uma prática de vida saudável a criança vai seguir o exemplo, dessa forma é importante a realização de atividades físicas cotidianamente e mudança de hábitos alimentares. Do ponto de vista de Warkentin, Mais, Latorre, Carnell e Taddei (2018), instruir os pais sobre o peso de seus filhos deve ser um primeiro passo importante na promoção de um ambiente e estilo de vida saudável, bem como na prevenção e tratamento da obesidade infantil.

Bankoff, Bispo e Sousa (2020) cita que com o envelhecimento, fator incorrigível, as doenças crônicas não transmissíveis ocorrem muito cedo no indivíduo, o que já está acontecendo em nossa sociedade devido à obesidade, diabetes e hipertensão em crianças e adolescentes. Para Giuglian (2018), é importante enfatizar a importância de monitorar o desenvolvimento e os hábitos alimentares da criança desde os primeiros anos de vida, esses cuidados estabelecem uma prevenção de saúde na sua vida presente e futura. Portanto, é necessário manter hábitos saudáveis desde a infância, alimentarse corretamente, praticar atividades físicas e enfatizar a importância na redução da exposição à mídia, como televisão, internet, telefones celulares e computadores, evitando a possibilidade de influenciar negativamente nas escolhas alimentares. No entanto, o convívio familiar está menos frequento devido a ocupação dos pais ou cuidadores, sendo assim crianças e adolescentes ficam mais expostos aos meios virtuais quando não acompanhados ou monitoradas.

Ferreira, Szwarcwald e Damacena (2019) mencionam que a taxa de obesidade da população brasileira deve ser monitorada para compreensão dos padrões e fatores de risco, garantindo uma prevenção à obesidade infantil e promovendo hábitos saudáveis na sociedade brasileira, sendo fundamental o apoio a políticas públicas.

\section{Suplementos alimentares}

A Agência Nacional de Vigilância Sanitária (Anvisa) fornece como método a suplementação para suprir as necessidades nutricionais que não são atingidas por meio da alimentação para que possa alcançar o objetivo desejado. Com uma ampla variedade de suplementos no mercado atual, favorecendo o aumento da massa muscular, redução de gordura corpórea e também a recuperação pôs exercício (Oliveira, 2014).

Os suplementos alimentares caracterizam-se pelo consumo de nutrientes com grau de eficiência extremamente variável, proporcionado adaptações fisiológicas e melhora do desempenho físico, com isso os suplementos alimentares podem ser ergogênicos devido sua recuperação e sua preparação para o treino.

O consumo de suplementos alimentares cresce de maneira rápida com a finalidade tanto de aumento do rendimento esportivo quanto para melhoria da condição de saúde e estética (hipertrofia muscular). Os praticantes de musculação são os que mais utilizam suplementos alimentares, tendo como objetivo principal a hipertrofia muscular (Biesek, Alves \& Guerra., 2015).

Dos Reis, Camargos, Oliveira e Domingues (2017), realizaram uma pesquisa em relação a utilização de recursos ergogênicos e suplementos alimentares por praticantes de musculação em academias e constataram que o suplemento mais citado pelos praticantes entrevistados foi a proteína do soro do leite - whey protein. Já Da Cruz Júnior, de Sá, Leão, Souza e Tolentino (2018) relataram em seu estudo uma prevalência do uso contínuo de creatina por praticantes de musculação.

Fernandes e Machado (2016) cabe salientar que os atletas e praticantes de atividades físicas de alta intensidade, fazem 
uso de suplementação da glutamina, como uma forma de buscar eficácia do resultado de seus esforços físicos.

\section{Whey protein}

Uma pesquisa feita nessas últimas décadas, pode se observar as qualidades nutricionais sobre a proteína, no qual é fabricado a partir do soro do leite (Whey), um subproduto resultante da fabricação de queijos por coagulação da caseína. Possuindo um alto valor nutricional devido suas proteínas apresentar um teor de aminoácidos essenciais bem alto, sendo assim eficaz para a complementação de dietas principalmente por atletas, visando oferecer o desenvolvimento e a recuperação do musculo de uma forma mais rápida (Fischborn, 2009).

Durante décadas, essa parte do leite era dispensada pelas indústrias de alimentos. Somente a partir da década de 70, os cientistas passaram a estudar as propriedades dessas proteínas (Phillips, 2004). As proteínas do soro de leite são altamente digeríveis e rapidamente absorvidas pelo organismo, assim estimulando a síntese de proteínas sanguíneas e teciduais, a tal ponto que alguns pesquisadores classificaram essas proteínas como proteínas de metabolização rápida. Muito adequada para situações de estresses metabólicos em que a reposição de proteínas no organismo se torna emergencial, pois as proteínas de soro apresentam quase todos os aminoácidos essenciais em excesso as recomendações, exceto pelos aminoácidos aromáticos (fenilalanina, tirosina) que não aparecem em excesso, mas atendem as recomendações para todas as idades e também apresentam elevadas concentrações dos aminoácidos triptofano, cisteína, leucina, isoleucina e lisina (Sgarbieri, 2004).

\section{Creatina}

A creatina ( $\mathrm{Cr}$ ) é um composto nitrogenado natural muito similar aos aminoácidos que se combinam com o fosfato originando a fosfocreatina (Guillén Del Castillo \& Linares, 2002).

A creatina orgânica possui duas fontes, sendo por meio da síntese pelo próprio organismo, a partir de 3 aminoácidos e pela ingestão de alimentos (Redondo et al., 1996). Ou seja, o composto é sintetizado pelo fígado, pâncreas e rins a partir de diversos aminoácidos, como arginina, glicina e metionina (Barbany, 2002) e pode ser naturalmente encontrado em alimentos de origem animal, principalmente peixes, carnes e outros produtos animais como o leite e os ovos (Mújika \& Padilla, 1997), fornecendo cerca de $1 \mathrm{~g}$ de creatina ao dia (Mendes \& Tirapegui, 2002).

A maior parte da creatina é estocada no músculo esquelético, armazenada na forma livre (40\%) ou fosforilada (60\%) (Mendes \& Tirapegui, 2002). A creatina fosforilada exerce importante papel na contração muscular, pois é um fosfogênio de alta energia importante em exercícios muito intensos, sendo necessário cerca de dois gramas diários de creatina, para repor os estoques corporais (Williams, Kreider \& Branch, 2000).

Nesse sentido, a creatina tem sido considerada um suplemento nutricional efetivo na otimização do desempenho de atividades físicas, sendo utilizada em atividades de curta duração e alta intensidade (Mendes \& Tirapegui, 2002).

Isso porque, durante um exercício intenso, a sua quebra libera energia que é usada para regenerar o trifosfato de adenosina, que é um nucleotídeo responsável pelo armazenamento de energia em suas ligações químicas.

Aproximadamente 95\% do pool de creatina encontra-se na musculatura esquelética e sua regeneração após o exercício é um processo dependente de oxigênio. Estudos mostram que a suplementação com este composto pode aumentar o pool orgânico em 10 a 20\%, e este percentual é maior em atletas vegetarianos (até 60\%) (Mahan \& Raymond, 2017).

Estudos relatam que a suplementação com creatina ocasiona benefícios, como o rápido aumento da massa corporal, que pode ser explicado pela retenção hídrica intracelular; aumento de massa corporal magra e aumento de força corporal; melhora de performance e qualidade em treinos, principalmente de resistência física, pela diminuição da fadiga muscular (Zuniga et al., 2012).

Tais benefícios, demonstram a atuação da creatina no organismo, sendo um suplemento válido para quem busca ainda 
a hipertrofia muscular, uma vez que permite melhor desempenho durante a tividade física, por diminuir a fadiga, além de repor os estoques do corpo gastos durante a prática da atividade física.

Além disso, a creatina atua positivamente suprimindo as formações tumorais (Di Biase et al.,2019), no combate ao quadro depressivo, como fator neuroprotetor (Bakian, Huber, Scholl, Renshaw \& Kondo, 2020) e em situações de sarcopenia (perda da massa muscular), entre outras.

Entretanto, ainda existe controvérsia com relação aos benefícios e riscos da suplementação com esta substância (Mahan \& Raymond, 2017), sendo que a utilização da creatina como suplemento, não é recomendada para pacientes com histórico de doenças renais, uma vez que há poucos estudos nessa área (Vega \& Huidobro2019).

\section{Glutamina}

A glutamina é o aminoácido livre mais abundante no plasma e é encontrado também em altas concentrações $(0,5$ a 0,9 $\mathrm{mmol} / \mathrm{L}$ ) em diversos tecidos corporais humanos (Cruzat, Petry \& Tirapegui, 2009).

O tecido muscular é o tecido mais relevante na síntese, estoque e liberação de glutamina, uma vez que, aproximadamente $80 \%$ da glutamina corporal encontra-se no músculo esquelético e exerce um papel fundamental na manutenção da glutamina plasmática. Ressalta-se ainda que o músculo esquelético libera cerca de $50 \mathrm{mmol} / \mathrm{h}$ de glutamina na circulação, tendo assim, papel metabólico essencial na regulação da glutaminemia (Gleeson, 2008).

As duas principais enzimas participantes do metabolismo da glutamina são a sintetase, responsável por catalisar a conversão de glutamina a partir de amônia e glutamato, na presença de ATP e a glutaminase, responsável pela hidrólise da glutamina, convertendo-a em glutamato e amônia. (Novelli, Strufaldi, Rogero \& Rossi, 2007).

Quando a ingestão de glutamina é superior à sua síntese, alguns órgãos são afetados, principalmente o músculo esquelético, pulmões, fígado e cérebro, por estarem envolvidos diretamente no processo de síntese e liberação deste aminoácido (Nelson, Robinson, Koning \& Buse, 1997).

Com base nas elevadas atividades de enzimas, os rins e intestino, são considerados tecidos consumidores de glutamina, pela atividade de glutaminase (Hellbrugge \& Ornellas, 2010). Enquanto, que os músculos esqueléticos, os pulmões, o fígado, o cérebro e, o tecido adiposo, são considerados sintetizadores de glutamina, pela atividade da enzima glutamina sintetase (Hellbrugge \& Ornellas, 2010; Simon \& Liberali, 2012).

Apesar de muito utilizada para fins nutricionais, a glutamina vem sendo indicada como suplemento para atletas e indivíduos ativos. Tal indicação é feita em situações onde há intenso catabolismo, tal como em exercícios prolongados e de alta intensidade. Isso porque, esse tipo de exercício reduz a concentração de glutamina, podendo causar disfunções de imunidade aumentando a susceptibilidade à infecção (Gleeson, 2008), podendo ocasionar ainda imunodepressão em atletas de resistência (Cruzat, Petry \& Tirapegui, 2009).

Percebe-se assim, que a glutamina atua de forma a beneficiar o sistema imunológico, sendo, a manutenção da concentração plasmática de glutamina necessária para preservar a homeostase do sistema imune (Cruzat, Petry \& Tirapegui, 2009).

Outras situações que levam a um quadro de insuficiência de glutamina no organismo são as infecções, cirurgias, trauma, acidose e exercícios exaustivos, onde a homeostase de glutamina é colocada sob situação de estresse, e as reservas de glutamina, são depletadas (Novelli, Strufaldi, Rogero \& Rossi, 2007).

De um modo geral, a glutamina tem papel fundamental no organismo, tendo em vista funções liagadas à proliferação e desenvolvimento de células, transporte da amônia entre os tecidos, participação no sistema antioxidante, transferência de nitrogênio entre órgãos, melhora na permeabilidade e integridade intestinal, aumento da resistência à infecção por aumento da função fagocitária, dentre outras (Rogero, Tirapegui, Pedrosa, Castro \& Pires, 2006). 


\section{Hipercalóricos e energéticos}

Os carboidratos são responsáveis por metade do total de calorias das refeições, de suma importância para a dieta, e por manter o a reserva energética necessária para o funcionamento do corpo e também para as atividades físicas. Eles podem ser divididos em monossacarídeos (glicose e frutose), dissacarídeos (lactose, maltose, sacarose) e polissacarídeos, considerados os mais complexos da classificação citada, a exemplo da maltodextrina (Silva et al., 2011).

Esses carboidratos são utilizados como fonte energia durante as atividades físicas e/ou aquelas que necessitem do gasto de energia, mas quando não consumido da forma adequada pode causar como consequência várias situações, dentre elas uma diminuição na performance física. A utilização de carboidratos durante e após os exercícios físicos causam alterações hormonais, que normalmente são benéficas para o organismo, como a reposição do glicogênio muscular, evitando uma hipoglicemia pelo gasto excessivo de energia (Alves \& Navarro, 2010).

No mercado é possível encontrar muitos suplementos a base de carboidratos, que são utilizados para atingir as recomendações necessárias do organismo, tendo comprovação dos benéficos, mas que sempre é alertado aos consumidos de que sua utilização não substitui uma refeição equilibrada e adequada, é necessário cautela na utilização, pois o consumo exagerado do mesmo pode causar o surgimento de acne em diversas partes de corpo (Alves \& Navarro, 2010).

Os hipercalóricos são suplementos que possuem em sua composição carboidratos, vitaminas, minerais e por fim proteínas de alto valor biológico, variando de acordo com seu fabricante. Por ser considerada fonte de calorias, são bastante consumidos pelos praticantes de atividades físicas como aporte calórico ou com a intenção de ter aumento no peso corpóreo (Freitas, Costa \& Costa, 2017).

Podem ser utilizados para completar a refeição dos usuários, caso essa não possa ser realizada, mas em outros casos são usados na substituição de uma refeição importante como o café da manhã, almoço ou jantar, o que não é indicado pelos profissionais da saúde (Cardoso et al., 2011).

Dessa forma, mesmo com estudos mostrando mudanças positivas na reposição de estoques energéticos e melhora no metabolismo, o uso inadequado e sem orientação correta pode surgir resultados contraditórios, por isso é necessário bastante cuidado na utilização (Kremer \& Kremer, 2013). A maltodextrina é apontada como o suplemento mais utilizado dentro do grupo de carboidratos, sendo um polímero de glicose usado nas bebidas de esportistas, preparada pela hidrólise controlada do amido, com variação na concentração de 5 a $20 \%$ (Costa et al., 2010).

A digestão da maltodextrina começa na cavidade bucal, pela ação da amilase salivar, mas é uma exceção quando comparada a outros oligossacarídeos, pois possui um elevado índice glicêmico. Sendo assim, tem um papel importante na manutenção dos níveis glicêmicos de atletas que gastam uma elevada quantidade de glicose nas suas atividades físicas. A maltodextrina atua cerca de 30 minutos após ingestão nos níveis glicêmicos, convertendo-se em glicose e assim aumentando os níveis glicêmicos (Cardoso et al., 2011).

\section{Alimentação para hipertrofia}

A alimentação adequada juntamente com a prática do exercício físico é de fundamental importância na busca da hipertrofia muscular. A prática do treinamento resistido tem sido bastante estimulada, sobretudo pelos benefícios que esta proporciona a saúde e ao condicionamento físico humano (Andrade \& Fernandes, 2011).

Diante da base fisiológica, o exercício físico conta muito em relação ao aumento ou emagrecimento do corpo, mas somente treino não basta, a alimentação tem grande relevância na base de $70 \%$ na contribuição para o aumento de peso, sendo o treino com influência de aproximadamente 30\%. Segundo Santos, Ribeiro e Liberali (2011), essa busca por um corpo perfeito e uma vida saudável, a alimentação balanceada associada à prática de exercício físico, vem exercendo forte influência no comportamento das pessoas, tanto entre aquelas preocupadas com estética, quanto os que visam qualidade de vida. 
Ressaltam também sobre a intervenção nutricional que se adéqua como suporte para melhora do desempenho físico em diversas modalidades de exercícios físicos.

Porém, para obter estes resultados e para evitar complicações a curto e longo prazo como fadiga muscular, hipoglicemia e deficiências nutricionais, é necessário

seguir uma alimentação adequada em macro e micronutrientes de acordo com as necessidades nutricionais individuais (Rossi \& Tirapegui,1999). Cada ser humano tem sua individualidade biológica, então para cada corpo uma reação, diante disso, o profissional de nutrição exercer sua função de mediador para orientar, avaliar e planejar a alimentação dos pacientes.

Para que seja saudável a alimentação deve conter todos os grupos alimentares como: carboidratos, proteínas, lipídios, fibras, vitaminas e minerais (Guimarães \& Oliveira, 2014). Esses nutrientes são essenciais para o corpo humano se manter saudável, seguindo uma estrutura nutricional com foco na hipertrofia, além da alimentação como base tem também outros critérios como o biótipo de cada pessoa. Uma dieta receitada para diferentes categorias somatotipo: ectomorfo, mesomorfo e endomorfo, cada um desses serão receitas distintas sendo para objetivos de hipertrofia.

A atividade física é de fundamental importância para a melhoria da saúde e, consequentemente, da qualidade de vida, quando realizados de maneira correta (Prazeres, 2007). Desde o início desta pesquisa, vem se mostrando que a junção de alimentação e treino promovem resultados significantes para o corpo humano. Percebe-se que a cada dia o ser humano fica com menos tempo para fazer alimentação de forma correta, seguindo horários e quantidade necessária de nutrientes, desta forma, alguns recorrem para suplementações alimentares para tentar controlar esse declínio alimentar.

É importante ressaltar, que as decisões tomadas acerca de uma boa alimentação e com adição de suplementação, deve ser realizada sob orientação de um nutricionista. Isso porque, é importante seguir uma alimentação balanceada, consumindo a quantidade de nutrientes que o corpo necessita para poder desenvolver a musculatura (hipertrofia). Esse é um processo contínuo e duradouro, e requer muita dedicação e persistência por parte das pessoas que se submetem a seguir uma alimentação com intuito de hipertrofia muscular, devendo assim, seguir as recomendações médicas de alimentação, uma vez que é imprescindível nesse processo.

\section{Carboidratos}

O consumo de carboidrato varia de acordo com a necessidade de cada pessoa, a recomendação para pessoas fisicamente ativas é de 55-60\% de carboidratos, as que treinam intensamente deve consumir de $60-70 \%$ de carboidratos nas calorias diárias, é preferível consumir carboidratos ricos em fibras como grãos e vegetais, o consumo de carboidrato pode minimizar as transformações negativas do sistema imunológico em razão ao exercício físico.

Antes do exercício o praticante deve consumir uma refeição rica em carboidrato para a manutenção da glicose sanguínea, e também rica em liquido para manter a hidratação do corpo durante a atividade, deve ter uma baixa quantidade de gorduras e fibras pois elas podem ocasionar no esvaziamento gástrico e estresse gastrointestinal, a utilização de estratégia rica em carboidrato antes da pratica de exercício aumenta a reserva de glicogênio muscular, assim obtendo um bom desempenho e garantindo energia o suficiente para pratica de atividade física (Oliveira, 2014).

\section{Proteínas}

O consumo de proteínas para atletas de endurance é de 1,2 a $1,4 \mathrm{~g} / \mathrm{kg}$, atletas de força é de 1,6 a 1,7, e atletas ultradurence pode chegar até $2 \mathrm{~g} / \mathrm{kg}$. Em uma alimentação balanceada essas quantidades podem ser supridas tranquilamente e não necessitando fazer reposições com uso de suplementos alimentares proteicos, alimentos de origem animal são boas fontes proteicas e além do mais possuem todos os aminoácidos essenciais, alguns vegetais são ricos em proteínas, como proteína de soja e derivados, cereais e leguminosas. 
As proteínas estão relacionadas a um melhor estímulo da síntese proteica muscular, quando consumidas em conjuntos com carboidratos como combinações de arroz e feijão, resulta em um maior desempenho físico e menor dano muscular, assim obtendo maior desempenho do exercício físico e hipertrofia muscular (Lima \& Santana, 2014).

\section{Lipídeos}

O consumo de gordura deve variar de $20 \%$ a $30 \%$ do consumo total de energia, que é aproximadamente de $1 \mathrm{~g}$ de lipídeo por kg de peso corporal. Consumir menos que $20 \%$ não beneficia o desenvolvimento, pois a gordura é fundamental elas são veículos de vitaminas lipossolúveis e ácidos graxos essenciais e é de grande fundamento na dieta dos atletas. Dietas muito rica em gordura não são recomendadas pois são de difíceis digestibilidade assim aumentando a probabilidade de ganho de peso aumentando a quantidade total de energia da dieta (Acsm, 2009).

A gordura é um composto fundamental na dieta pois é responsável por fornecimento de energia e outros nutrientes essenciais que estão ligados à membrana celular, como vitamina E, D e E (IOM, 2005). As diretrizes dietéticas 2005 $(\mathrm{NYH}, 2009)$ e as do Canadá $(\mathrm{HCW}, 2008)$ fazem as recomendações gerais que devem ser seguidas por atletas, conforme mostra a Tabela 1.

Tabela 1. Requerimento de lipídeos.

\begin{tabular}{cc}
\hline PERCENTUAL DO VET: 25 A 30\% (NUNCA INFERIOR A 20\%) \\
\hline Tipo de lipídeo & Recomendação de ingestão \\
Lipídeos totais (máximo) & 1 g\kg\dia \\
Ácidos graxos essenciais & 8 a 10g\dia \\
Saturados & $10 \%$ do total de calorias \\
Monoinsaturados & $10 \%$ do total de calorias \\
Poli-insaturados & $10 \%$ do total de calorias \\
\hline
\end{tabular}

Fonte: Santos (2014).

Dessa maneira, a proporção de energia do valor energético total fornecida a partir de ácidos graxos é de $10 \%$ compostas pelos saturados, $10 \%$ poliinsaturados e $10 \%$ monoinsaturados, incluindo pontes de ácidos graxos essenciais, em que que deve ocorrer variação de 8 a $10 \mathrm{~g}$ por dia.

\section{Vitaminas e minerais}

Os micronutrientes executam um papel fundamental nas vias metabólicas e produção energia, na síntese de hemoglobina e na manutenção da saúde óssea, elas têm uma função imunológica e protegem o organismo contra danos, elas ajudam a melhorar a recuperação de exercício e lesões. Em caso de exercícios muito intensos ocorrem adaptações bioquímicas no musculo assim necessitando de uma quantidade maior de micronutrientes (ACSM, 2009). Com uma ingestão maior de nutrientes elas suprem as necessidades do organismo assim ocasionando um aumento de massa muscular (ACSM, 2009).

Os suplementos de vitaminas e minerais nem sempre são necessários, quando a dieta consegue um total adequado de energia que suprem as demandas do exercício, assim conseguindo manter o peso corporal com uma dieta adequada e variações de alimentos. Quando os atletas restringem o consumo de energia e elimina nutrientes da dieta resultam em perda de peso severa, quando isso ocorre tem que incluir uma suplementação isolada ou conjunta de um ou mais micronutrientes. Quando a dieta é seguida corretamente suprindo as necessidades do organismo, não é necessário o consumo de suplementos vitamínicos e minerais pois não melhora o desempenho (ACSM, 2009).

\section{Hidratação durante o exercício}


A hidratação é um fator essencial durante a prática de exercício, sendo assim, é importante saber o estado de hidratação antes, durante e após a atividade física, quando é praticado com constância deve sempre avaliar o estado de hidratação para que não corra o risco de problemas de saúde decorrente da desidratação. Tem várias formas de calcular a desidratação, uma delas é a variação do peso corporal antes, durante e após as atividades físicas, outro método utilizado é análise da coloração da urina (Machado-Moreira, Vimieiro-Gomes, Silami-Garcia \& Rodrigues, 2006).

O estado de hidratação adequada, varia seu nível, de acordo com o peso corporal de cada pessoa e deve ser levado em consideração algumas características como coloração e gravidade específica da urina, como mostra a Tabela 2.

Tabela 2. Índices de estado de hidratação.

\begin{tabular}{cccc}
\hline Estado de hidratação & \% peso corporal & Coloração da urina & $\begin{array}{c}\text { Gravidade específica } \\
\text { da urina }\end{array}$ \\
Eu-hidratação & $+1 \mathrm{a}-1$ & 1 ou 2 & maior 1.010 \\
Desidratação mínima & $-1 \mathrm{a}-3$ & 3 ou 4 & $1.010-1.020$ \\
Desidratação significativa & $-3 \mathrm{a}-5$ & 5 ou 6 & $1.021-1.030$ \\
Desidratação grave & maior -5 & maior 6 & maior 1.030 \\
\hline
\end{tabular}

Fonte: Santos (2014).

O aumento da temperatura pode ocasionar dois tipos de respostas durante a atividade física, em baixo nível ocasiona desconforto e fadiga, já em alto nível ocasiona uma grande redução do desempenho. Além do mais se haver um estresse prolongado pode ocorrer desidratação e redução do volume do sangue, a desidratação é um dos causadores de estresse ocasionados pelos exercícios físicos, passando a ter respostas menos expressiva e o organismo fica mais vulnerável a doenças (Santos, Adriano, Lopes \& Vitalino, 2011)

A hidratação durante atividade física serve para diminuir os danos causados pela desidratação, não possui quantidade especifica de reidratação devido as diferenças e características de cada exercício, então é sugerido que os atletas observem a perca de peso corporal no treinamento, para estimar a quantidade ideal dos líquidos que foram perdidos e assim fazendo uma hidratação adequada, pode incluir bebidas repositoras que contem sódio e potássio, elas auxiliam na reposição de elétrons perdidos pelo suor estimulando a sede e assim ocasionando uma maior ingesta de agua (Cheuvront, Montain \& Sawka, 2007).

\section{Massa muscular}

A nutrição tem um papel fundamental no desempenho físico em praticantes de musculação; as atividades metabólicas desses praticantes são mais intensas que comparada a pessoas sedentárias, devendo assim ter mudanças na alimentação para que não ocorra prejuízo no desempenho. Por isso é de grande importância se alimentar corretamente, também é de grande importância salientar quanto à duração, frequência, tipo e intensidade do exercício (Hirschbruch \&Carvalho, 2008).

A ingestão insuficiente de calorias, sem a ingestão correta de calorias diárias é impossível ganhar massa muscular, além disso, a ingestão excessiva de calorias e balanço errôneo de macro nutriente (carboidratos, proteínas e gorduras), um grande exemplo: a ingestão de muita gordura e carboidrato chegando a esquecer das proteínas, isso vai levar ao aumento de gordura e pouco ganho de massa muscular. Contudo, entendemos que a melhor alimentação para hipertrofia é a alimentação estruturada.

A alimentação feita corretamente, que inclua os nutrientes denominados macronutrientes: carboidratos, proteínas e lipídeos, proporcionam ao praticante do exercício, energia que preserva as funções metabólicas durante o repouso e na atividade física. Além de sua função como fornecedores de energia biológicos tais nutrientes ainda preservam as características funcionais e estruturais do organismo (Mcardle \& Katch, 2011).

Entendemos a partir disso, que a nutrição tem uma porcentagem significante no processo de desenvolvimento do 
corpo, contudo, os micros e macro nutrientes possibilitam energia e crescimento para o indivíduo, então ao treinar com o objetivo de hipertrofia pode-se alcançar resultados satisfatórios quando bem orientado tanto na alimentação quanto nos treinos.

Conforme Mcardle, Katch e Katch (2013), cada indivíduo necessita de um nível de energia para desempenhar as funções vitais no estado acordado. Essa demanda de energia - denominada taxa metabólica basal (TMB), reflete a produção de calor pelo corpo. Diante disso, reflete a suma importância do consumo adequado de alimentos necessários para o desenvolvimento corporal, independente do objetivo do qual o indivíduo pretende alcançar é imprescindível à alimentação adequada para as funções vitais.

Independentemente do que se pretende alcançar a nutrição adequada é fundamental tanto para indivíduos envolvidos com a prática de exercícios físicos, como desportiva, e colabora para a promoção e manutenção da saúde, além de favorecer o funcionamento de vias metabólicas associadas ao exercício físico.

A hipertrofia traduz-se num crescimento dos elementos contráteis, que ficam maiores, e uma expansão da matriz extracelular para suportar esse crescimento. Um estímulo suficiente que potencie este acontecimento, principalmente ingestão proteica associada ao exercício físico de resistência/força, leva ao desencadear de uma cadeia de fenômenos miogênicos, que levam a um aumento de tamanho e quantidade de proteínas miofibrilares contráteis actina e miosina, e do número total e sarcômeros em paralelo, levando a um crescimento das fibras individuais e, consequentemente, a um aumento de tamanho do músculo.

Salientando a hipertrofia ainda com influência da alimentação, Oliveira (2014), ressalta que a alimentação adequada é essencial para melhorar ou manter o treinamento e a performance. No entanto, muitos praticantes de exercício físico alteram seu comportamento dietético sem orientação do profissional habilitado e sim sobre influência de treinadores ou professores de educação física, amigos ou mídia que não são habilitados para prescrever dietas, podendo resultar em escolha alimentar inadequada principalmente no momento anterior e posterior ao treino.

Além disso, o nível de atividade física representa o fator mais importante que exerce impacto sobre o dispêndio diário de energia.

Sendo assim, é de total responsabilidade a prescrição de dieta por parte do profissional de nutrição, dispensando qualquer outro profissional para orientações nutricionais. Infelizmente grande parte da sociedade não tem a consciência da importância do profissional de nutrição, porém, com o tempo muitos vem procurando mais e mais.

O tecido muscular esquelético exibe uma plasticidade e capacidade de adaptação notáveis. As proteínas do músculo esquelético estão em contínuo processo de remodelação, através dos processos simultâneos de síntese de proteína muscular (SPM) e degradação de proteína muscular (DPM). Esta remodelação é um pré-requisito para o aumento de MME, e este aumento acontece quando a SPM excede a DPM. A ingestão proteica é um estímulo fundamental para a preservação/aumento de MME, regulado pela disponibilidade extra e intracelular de aminoácidos.

\section{Considerações Finais}

Em virtude dos fatos mencionados a regulação da resposta do balanço proteico-muscular, após exercício, à ingestão de nutrientes é mais complexa que uma simples quantificação da ingestão proteica, havendo outros fatores (tipo de a.a., propriedades digestivas das proteínas, timing da ingestão de nutrientes em relação ao período de exercício, co-ingestão de outros nutrientes e ingestão energética total) que influenciam o metabolismo muscular. Assim, para qualquer quantidade de proteína ingerida, a resposta do anabolismo proteico varia, a depender do que é ingerido, bem como do momento da ingestão.

Porém, no que se refere às quantidades, apesar das evidências indicarem o contrário, métodos que quantificam o balanço do azoto, idênticos aos utilizados em sedentários, mostram que indivíduos ativos necessitam ingerir maior quantidade de proteína. No entanto, uma vez que a grande maioria dos atletas já consomem esta quantidade em sua dieta 
habitual, torna-se desnecessária a recomendação para o aumento da ingestão proteica. Pois, mais importante que a recomendação acerca da quantidade, está a indicação do tipo e timing de ingestão.

Além da ingestão proteica, a ingestão energética adequada parece ser determinante para a obtenção de uma resposta anabólica. Deste modo, quando o objetivo primário for a hipertrofia muscular, a recomendação mais importante deverá ser uma alimentação hiper energética, uma vez que a quantidade de energia a fornecer dependerá da intensidade, duração e cronicidade do treino, o que faz com que seja difícil estabelecer um número exato e comum a todos.

Em vista dos argumentos apresentados, a presença de um profissional de nutrição se reveste de tamanha importância, pois não há números nem algoritmos que permitam a aplicação de uma metodologia a todos os atletas, sendo cada caso particular, tendo em vista objetivos individuais, que variam a cada indivíduo.

Levando em conta o que foi observado, conclui-se assim, que o acompanhamento nutricional é crucial para permitir o bom estado nutricional, assim como para alcançar a composição corporal ideal e, deste modo, possibilitar a otimização do rendimento desportivo ambicionada por todos os intervenientes no mundo desportivo, bem como intervir na preservação da saúde.

Nesse sentido, para trabalhos futuros, sugere-se que a abordagem da nutrição alimentar traga meios facilitadores de divulgação das informações para a população em geral, em especial aos esportistas com foco na hipertrofia. Além disso, estudos comparativos entre os adeptos da alimentação saudável regular e os não regulares, demonstrando os ganhos reais de massa muscular em dado período de observação, de forma a validar a importância da escolha dos alimentos na hipertrofia.

\section{Referências}

Alves, S. C. R. \& Navarro, F. (2010). O uso de suplementos alimentares por frequentadores de academias de Potim - SP. Revista Brasileira de Nutrição Esportiva, 4(20), 139-146. http://www.rbne.com.br/index.php/rbne/article/view/174

American College of Sports Medicine- ACSM. (2009). Nutrition and Athletic Performance. Medicine \& Sience in Sports \& Exercise. Dietetic Association, and Dietitians of Canada. https://doi.org/10.1249/MSS.0b013e318190eb86

Amaral, C. M. C. (2008). Educação alimentar. FMPB. Fundação Passos Barros www.fmpb.org.br/mostraconteudos.asp?cod_conteudo=6

Andrade, C. L. \& Fernandes, A.R. (2011). Treinamento com pesos e promoção da saúde em adultos: uma revisão sistemática da literatura nacional acerca dos métodos empregados em estudos científicos. Revista Colloquium Vitae, 3(2), 59-66. 2011. https://journal.unoeste.br/index.php/cv/article/view/678

Antunes, H. K. M., Andersen, M. L., Tufik, S. \& Mello, M. T. (2008). Privação de sono e exercício físico. Revista Brasileira de Medicina do Esporte, 14, 5156. https://doi.org/10.1590/S1517-86922008000100010

Bakian, A. V., Huber, R. S., Scholl, L., Renshaw, P. F., \& Kondo, D. (2020). Dietary creatine intake and depression risk among US adults. Translational psychiatry, 10(1), 1-11. https://doi.org/10.1038/s41398-020-0741-x

Barbany, J. R. (2002). Alimentación para el deporte y la salud. Barcelona: Martínez Roca. http://www.paidotribo.com/es/nutricion/1116-alimentacion-para-eldeporte-y-la-salud.html

Bicalho, E., De Almeida, A. L. \& Gomes, D. V. (2020). Efeitos fisiológicos decorrentes do jejum intermitente. JIM-Jornal de Investigação Médica, 1(2), 022031. https://doi.org/10.29073/jim.v1i2.290

Biesek, S., Alves, L. A. \& Guerra, I. (2015). Estratégias de Nutrição e Suplementação no Esporte. (3a ed.), Manole.

Brasil. (1999). Ministério da Saúde. Gabinete do Ministro. Portaria n. ${ }^{\text {7 }}$ 710, de 10 de junho de 1999. Aprova a Política Nacional de Alimentação e Nutrição. Diário Oficial da União,Poder Executivo, Brasília, DF.

Brasil. (2010a). Ministério da Saúde. Agência Nacional de Vigilância Sanitária. Resolução RDC n 18 , de 27 de abril de 2010 . Dispõe sobre alimentos para atletas. Diário Oficial da União, Brasília, n. 79, Seção 1. 211, 28.

Brasil. (2010b). Ministério da Saúde. Agência Nacional de Vigilância Sanitária. Resolução RDC n 42 , de 29 de agosto de 2010 . Dispõe sobre alimentos para atletas. Diário Oficial da União, Brasília, n. 79, Seção 1. 211

Brasil. (2006). Ministério Da Saúde E Ministério Da Educação. Portaria Interministerial. MS/MEC n. 1010 de 08/05/2006. Institui as diretrizes para a Promoção da Alimentação Saudável nas Escolas de educação infantil, fundamental e nível médio das redes públicas e privadas, em âmbito nacional. http://dtr2001.saude.gov.br/sas/PORTARIAS/Port2006/GM/GM-1010.htm.

Brasil. (2006). Ministério da Saúde. Cadernos de Atenção Básica. №12. Brasília.

Brasil. (2018). Ministério da Saúde. Conselho Federal de Farmácia. Resolução n 661, de 25 de outubro de 2018 . Dispõe sobre cuidados farmacêuticos 
relacionados a suplementação alimentar e demais categorias de alimentos. Diário Oficial da União, Brasília, n. 210, Seção 1. 122, 31.

Brito, G. H. S. (2020). Os efeitos da suplementação de creatina no organismo. Trabalho de Conclusão de Curso de Graduação. Pontifícia Universidade Católica de Goiás - PUC Goiás. https://repositorio.pucgoias.edu.br/jspui/bitstream/123456789/340/1/TCC\%20Gustavo\%20vers\%C3\%A3o\%20final.pdf

Cheuvront, S. N., Montain, S. J. \& Sawka, M. N. (2007). Fluid replacement and performance during the Marathon. 37, 353-357. https://doi.org/10.2165/00007256-200737040-00020

Cardoso F. I. C. S., Santos, A. M. L., Adriano, L. S., Lopes, R. S., Vitalino R. \& Sá, N. A. R. (2011). A importância da hidratação hidroeletrolítica no esporte. Revista brasileira de ciência e movimento, 19(3), 120-128

CONSEA. (2004). Alimentação e educação nutricional nas escolas e creches. In: Conferência Nacional de Segurança Alimentar, (2a ed.), Olinda. Relatório final. Olinda.

Cordeiro, R., Salles, M. B. \& Azevedo, B. M. (2017). Benefícios e malefícios da dieta low carb. Revista Saúde em Foco, 9, 714-722. https://portal.unisepe.com.br/unifia/wp-content/uploads/sites/10001/2018/06/080_beneficios.pdf

Cruzat, V. F., Petry, E. R. \& Tirapegui, J. (2009). Glutamina: Aspectos Bioquímicos, Metabólicos, Moleculares e Suplementação. Revista Brasileira de Medicina do Esporte, 15(5), 392-397. https://doi.org/10.1590/S1517-86922009000600015

Curi, R., Lagranha, C. J., Doi, S. Q., Sellitti, D. F., Procopio, J., Pithon-Curi, T. C., Corless, M. \& Newsholme P. (2005). Molecular Mechanisms of Glutamine Action. Journal of Cellular Physiology, 204, 392-401. https://doi.org/10.1002/jcp.20339

Da Cruz Júnior, E. G., de Sá, F. O., Leão, L. L., Souza, N. S., \& Tolentino, G. P. (2018). Perfil dos usuários de creatina frequentadores de academias de musculação. Revista Brasileira de Nutrição Esportiva, 12(76), 980-984. http://www.rbne.com.br/index.php/rbne/article/view/1186

Dartora, N., Valduga, A. T. \& Venquiaruto, L. (2006). Alimentos e saúde: uma questão de educação. Vivências. Erechim,1(3),201-212.

Di Biase, S., Ma, X., Wang, X., Yu, J., Wang, Y.C., Smith, D. J., Zhou, Y., LI, Z., Kim, Y. J., Clarke, N., To, A. \& Yang, L. Creatine uptake regulates CD8 T cell antitumor immunity. Journal of Experimental Medicine, 216(12), 2869-2882. https://doi.org/10.1084/jem.20182044

Dos Reis, E. L., Camargos, G. L., Oliveira, R. A. R., \& Domingues, S. F. (2017). Utilização de recursos ergogênicos e suplementos alimentares por praticantes de musculação em academias. RBNE - Revista Brasileira De Nutrição Esportiva, 11(62), 219-231. http://www.rbne.com.br/index.php/rbne/article/view/770

Fernandes, W. N. \& Machado, J. S. (2016). Uso de suplementos alimentares por frequentadores de uma academia do município de Passo Fundo- RS. Revista Brasileira de Nutrição Esportiva, 10(55), 59-67. http://www.rbne.com.br/index.php/rbne/article/view/607

Fischborn, S. C. (2009). A influência do tempo de ingestão da suplementação de whey protein em relação à atividade física. Revista Brasileira de Nutricão Esportiva, 3(14), 7. http://www.rbne.com.br/index.php/rbne/article/view/109

Freitas, I. K. P. C., Costa, J. L. \& Costa, C. L. S. (2017). Suplementação Esportiva:Levantamento dos Suplementos mais Vendidos em Teresina-PI e Avaliação de Composição. Revista Saúde em Foco, 4(2), 129-148. http://dx.doi.org/10.12819/rsf.2017.4.2.8

Gerhardt, T. E. \& Silveira, D. T. (2009). Métodos de pesquisa / [organizado por] coordenado pela Universidade Aberta do Brasil - UAB/UFRGS e peloCurso de Graduação Tecnológica - Planejamento e Gestão para o Desenvolvimento Rural da SEAD/UFRGS. Editora da UFRGS. https://lume.ufrgs.br/handle/10183/52806

Gleeson, M. (2008). Dosing and Efficacy of Glutamine Supplementation in Human Exercise and Sport Training. The Journal of Nutrition, 138, 2045S-2049S. https://doi.org/10.1093/jn/138.10.2045S.

Gonçalves, W. B. \& Rocha, J. (2019). Benefícios da musculação, alimentação e suplementação para ganho muscular em jovem de 22 anos. Revista de Iniciação Científica da Universidade Vale do Rio Verde, 8(2). http://periodicos.unincor.br/index.php/iniciacaocientifica/article/view/5573

Goston, J. L. (2011). Recursos Ergogênicos Nutricionais: Atualização sobre a Cafeína no Esporte. Nutrição e Esporte, [S.I.], 1-6.

Goulart, R. M. M., Banduk, M. L. S. \& Taddei, J.A. A. C. (2010). Uma revisão das ações de nutrição e do papel do nutricionista em creches. Rev. Nutr., Campinas, 23(4), 11. https://doi.org/10.1590/S1415-52732010000400015

Guillén Del Castillo, M. \& Linares, G. (2002). Bases biológicas y fisiológicas del movimiento humano. Panamericana. https://dialnet.unirioja.es/servlet/libro?codigo $=4769$

Guimarães, L. M. \& Oliveira, D. S. (2014). Influência de uma alimentação saudável para a longevidade e prevenção de doenças. Interciência \& Sociedade (ISSN: 2238-1295), 3(2). https://revista.francomontoro.com.br/intercienciaesociedade/article/view/68

Hellbrugge, A. \& Ornellas, F. H. (2010). Infecções do Trato Respiratório Superior Causadas pelo Exercício Físico: Suplementação com Glutamina Previne esta Complicação? Revista Brasileira de Nutrição Esportiva, 4(19), 36-43. http://www.rbne.com.br/index.php/rbne/article/v iew/162/160

Hirschbruch, M. D. (2014). Nutrição Esportiva: uma visão prática. (3a ed.), Manole.

Hirshbruch, M. D. \& Carvalho, J. R. (2008). Nutrição esportiva: uma visão prática. ( 2a ed.), Manole.

Kremer, A. S. \& Kremer, G. S. (2013). Suplementação alimentar: análise deconsumidores em academias de musculação. XXI Seminário de iniciação cientifica, Salão do conhecimento. https://publicacoeseventos.unijui.edu.br/index.php/salaoconhecimento/article/view/2099/1758

Lima, J. \& Santana, P. C. (2014). Recomendação alimentar para atletas e esportistas. Coordenação de Esporte e Lazer. http://esporte.unb.br/images/PDF/2019/Alimentao_para_atleta_-_texto_atualizado.pdf 
Lüdke, M. \& André, Marli E. D. A. Pesquisa em educação: Abordagensqualitativas. EPU, 1986.

Machado-Moreira, C. A., Vimieiro-Gomes, C., Silami-Garcia, E. \& Rodrigues, L. O. C. (2006). Hidratação durante o exercício: a sede é suficiente? Revista Brasileira de Medicina do Esporte, 12, 405-409. https://doi.org/10.1590/S1517-86922006000600020

Mahan, L. K. \& Raymond, J. L. Krause. Elsevier Health Sciences Spain-T, 2017.

Martins, P. J. F., Mello, M. T. \& Tufik, S. (2001). Exercício e sono. Revista Brasileira de Medicina do Esporte, 7, 28-36.

Mcardle, W. D. \& Katch, F. I. (2011). Fisiologia do exercício: nutrição e desempenho humano; traduzido por Giuseppe Taranto. Guanabara Koogan.

Mcardle, W. D, Katch, F. I., \& Katch, V. L. Fisiologia do Exercício - Nutrição, Energia e Desempenho Humano. Editora Guanabara Koogan, 2013.

Mendes, R. R. \& Tirapegui, J. (2002). Creatina: o suplemento nutricional para a atividade física-Conceitos atuais. Departamento de Alimentos e Nutrição Experimental - Laboratório de Nutrição -Faculdade de Ciências Farmacêuticas - Universidade de São Paulo, 52(2). http://ve.scielo.org/scielo.php?script=sci_arttext\&pid=S0004-06222002000200001

Monteiro, P. H. N. \& Costa, R. B. L. (2004). Alimentação saudável e Escolas: possibilidadese incoerências. In: Qualidade de vida - Boletim do Instituto de Saúde, 32, 22.www.isaude.sp.gov.br. https://docs.bvsalud.org/biblioref/2020/03/1052384/bis-n32-qualidade-de-vida-22-22.pdf

Monteiro, P. H. N. \& Levy-Costa, R. B. (2004). Alimentação saudável e Escolas: possibilidades e incoerências. BIS, Bol. Inst. Saúde (Impr.), 22-22. https://pesquisa.bvsalud.org/portal/resource/pt/biblio-1052384

Moraes, R. C. M. (2016). Impactos de uma estratégia de jejum intermitente associada a treinamento de endurance na composição corporal e desempenho físico de ratos Wistar. http://bdtd.uftm.edu.br/handle/tede/229

Mújika, I. \& Padilla, S. (1997). Creatine Suplementation as an Ergogenic Aid for Sports Perfomance in Highly Trained Athletes: A Critical Review. International Journal of Sports Medicine, 18, 491-496. https://doi.org/10.1055/s-2007-972670.

Nelson, B. A., Robinson, K. A., Koning, J. S. \& Buse, M. G. (1997). Effects of exercise and feeding on the hexosamine biosynthetic pathway in rat skeletal muscle. American Journal of Physiology-Endocrinology and Metabolism, 272(5), E848-E855. https://doi.org/10.1152 / ajpendo.1997.272.5.E848.

Nofal, V. P., Kilson, A. C., Campos, F. G. C., \& de Miranda, P. A. C. (2019). Novas descobertas sobre a dieta low carb. e-Scientia, 12(1), 10-14. https://revistas.unibh.br/dcbas/article/view/2828

Novelli, M., Strufaldi, M. B.; Rogero, M. M. \& Rossi, L. (2007). Suplementação de Glutamina Aplicada à Atividade Física. Revista Brasileira de Ciência e Movimento, 15(1), 109-117. http://portalrevistas.ucb.br/index.php/RBCM/article/viewFile/737/740

Oliveira, R. A. (2014). Efeitos de uma dieta rica em carboidratos na hipertrofia muscular em praticantes de treinamento de força. Revista Brasileira de Prescrição e Fisiologia do Exercício (RBPFEX), v. 8(47), 4. http://www.rbpfex.com.br/index.php/rbpfex/article/view/643

Pereira A. S. et al. (2018). Metodología da pesquisa científica. UFSM.

Phillips, S. M. (2004). Requisitos de proteína e suplementação em esportes de força. Nutrição, 20 (7-8): 689-695. 10.1016 / j.nut.2004.04.009. PMID: 15212752 DOI: $10.1016 /$ j.nut.2004.04.009

Prazeres, M. V. (2007). A prática da musculação e seus benefícios para a qualidade de vida. Monografia (Graduação em Educação Física). UDESC. Florianópolis.

Redondo, D. R., Dowling, E. A., Graham, B. L., Almada, A. L. \& Williams, M. H. (1996). The effect of oral creatine monohydrate supplementation on running velocity. International Journal of Sports Nutrition, Sttutgart, 6(3), 213-221. https://doi.org/10.1123/ijsn.6.3.213

Rogero, M. M., Tirapegui, J. O., Pedrosa, R. G., Castro, I. A. \& Pires, I. S. O. (2006). Effect of Lalanyl-L-glutamine Supplementation on the Plasma and Tissue Concentrations of Glutamine in Rats Submitted to Exhaustive Exercise. Nutrition, 22, 564-571. https://www.scielo.br/j/rbcf/a/xDWhtysBjw947JycD3gJwmD/abstract/?lang=pt

Rossi, L. \& Tirapegui, J. (1999). Aspectos atuais sobre exercício fadiga e nutrição. Revista Paulista de Educação Física, 13(1), 67-82. https://doi.org/10.11606/issn.2594-5904.rpef.1999.137760

Santos, E. C, B., Ribeiro, F. E. O. \& Liberali, R. (2011). Comportamento alimentar pré treino de praticantes de exercício físico do período da manhã de uma academia de Curitiba - PR. Revista Brasileira de Nutrição Esportiva, São Paulo, 5(28), 305- 316. http://www.rbne.com.br/index.php /rbne/article/download/269/271

Santos, I. G. (2014). Nutrição. Clínica, Esportiva, Saúde Coletiva e Gestão de Qualidade em Serviços de Alimentação. Martinari.

Sgarbieri, V. C. (2004). Propriedades fisiológicas-funcionais das proteínas do soro de leite. Rev. Nutr., 17(4). https://doi.org/10.1590/S141552732004000400001

Silva, F. D., Santos, A. M., Adriano, L. S., Lopes, R. S., Vitalino, R., \& Sá, N. A. (2011). A importância da hidratação hidroeletrolítica no esporte. Revista brasileira de ciência e movimento, 19(3), 120-128. http://dx.doi.org/10.18511/rbcm.v19i3.1620

Simon, L. \& Liberali, R. (2012). Efeitos da Suplementação de Glutamina no Exercício Físico: Revisão Sistemática. Revista Brasileira de Nutrição Esportiva. 6(33), 193-201. http://www.rbne.com.br/index.php/rbne/article/v iew/300/303

Thomas, C., Ye, F., Irfanoglu, M., Modi, P., Saleem, K., Leopold, D. \& Pierpaoli, C. (2014). Supplement. Instituto Nacional de Saúde Mental, Bethesda. https://doi.org/10.1073/pnas.1405672111 
Research, Society and Development, v. 10, n. 14, e431101422041, 2021

(CC BY 4.0) | ISSN 2525-3409 | DOI: http://dx.doi.org/10.33448/rsd-v10i14.22041

Vega, J. \& Huidobro, J. P. (2019). Efectos en la función renal de la suplementación de creatina con fines deportivos, Rev. méd. Chile, 147(5). http://dx.doi.org/10.4067/S0034-98872019000500628

Williams M. H., Kreider R. B. \& Branch J. D. (2000). Creatina. Manole. 1.ed..

Zuniga, J. M., Housh, T. J., Camic, C. L., Hendrix, C. R., Mielke, M., Jhonson, G. O., Housh, DJ. \& Schimidt, R. J. (2012). The Effects of Creatine Monohydrate Loading on Anaerobic Performance and One-Repetition Maximum Strength. Journal of Strength and Conditioning Research. 26, $1651-1656$. http://dx.doi.org/10.1519/JSC.0b013e318234eba1 